\title{
Beta-Caryophyllene Exhibits Anti-Proliferative Effects through Apoptosis Induction and Cell Cycle Modulation in Multiple Myeloma Cells
}

\author{
Federica Mannino ${ }^{1}$, Giovanni Pallio ${ }^{1}{ }^{(\mathbb{C}}$, Roberta Corsaro $\left.{ }^{1} \mathbb{(}\right)$, Letteria Minutoli ${ }^{1}$, Domenica Altavilla ${ }^{2}$, \\ Giovanna Vermiglio $^{2}\left(\right.$ ) , Alessandro Allegra ${ }^{3}$, Ali H. Eid ${ }^{4,5}$, Alessandra Bitto ${ }^{1, *}$, Francesco Squadrito ${ }^{1, *}$ (i) \\ and Natasha Irrera ${ }^{1}$ (i)
}

Citation: Mannino, F.; Pallio, G.; Corsaro, R.; Minutoli, L.; Altavilla, D.; Vermiglio, G.; Allegra, A.; Eid, A.H.; Bitto, A.; Squadrito, F.; et al. BetaCaryophyllene Exhibits Anti-

Proliferative Effects through Apoptosis Induction and Cell Cycle Modulation in Multiple Myeloma Cells. Cancers 2021, 13, 5741. https:// doi.org/10.3390/cancers13225741

Academic Editors: Sikander Ailawadhi and Anupam Bishayee

Received: 12 October 2021

Accepted: 15 November 2021

Published: 16 November 2021

Publisher's Note: MDPI stays neutral with regard to jurisdictional claims in published maps and institutional affiliations.

Copyright: (c) 2021 by the authors. Licensee MDPI, Basel, Switzerland. This article is an open access article distributed under the terms and conditions of the Creative Commons Attribution (CC BY) license (https:/ / creativecommons.org/licenses/by/ $4.0 /)$.
1 Department of Clinical and Experimental Medicine, University of Messina, Via C. Valeria Gazzi, 98125 Messina, Italy; fmannino@unime.it (F.M.); gpallio@unime.it (G.P.); robi.corsaro@libero.it (R.C.); lminutoli@unime.it (L.M.); nirrera@unime.it (N.I.)

2 Department of Biomedical, Dental, Morphological and Functional Imaging Sciences, University of Messina, Via C. Valeria Gazzi, 98125 Messina, Italy; daltavilla@unime.it (D.A.); giovanna.vermiglio1@unime.it (G.V.)

3 Department of Human Pathology in Adulthood and Childhood, University of Messina, Via C. Valeria Gazzi, 98125 Messina, Italy; alessandro.allegra@unime.it

4 Department of Basic Medical Sciences, College of Medicine, QU Health, Qatar University, 2713 Doha, Qatar; ali.eid@qu.edu.qa

5 Biomedical and Pharmaceutical Research Unit, QU Health, Qatar University, 2713 Doha, Qatar

* Correspondence: abitto@unime.it (A.B.); fsquadrito@unime.it (F.S.)

Simple Summary: Multiple myeloma (MM) is a malignant B-cell neoplasm characterized by the uncontrolled proliferation of plasma cells. MM cells highly express cannabinoid type 2 receptors (CB2Rs), and previous studies have already demonstrated that the Cannabis plant and its derivatives may have anti-emetic as well as anti-neoplastic effects. In the present study, $\beta$-caryophyllene (BCP), a natural CB2R agonist, was evaluated for its anti-proliferative and anti-cancer effects. BCP was able to induce the apoptotic mechanism by activating the molecules involved in triggering apoptosis, such as Bax and caspase 3, and it reduced the anti-apoptotic protein Bcl-2; BCP also regulated cell proliferation through sophisticated crosstalk between Akt, $\beta$-catenin, and cyclin D1/CDK 4-6 in a concentration-dependent manner. These effects were counteracted by AM630, a CB2R antagonist, thus showing that BCP acts through CB2R. The data obtained so far demonstrate that BCP, thanks to its anti-proliferative effects, might represent an interesting additional therapeutic approach to improve anti-myeloma therapy.

Abstract: Cannabinoid receptors, which are widely distributed in the body, have been considered as possible pharmacological targets for the management of several tumors. Cannabinoid type 2 receptors (CB2Rs) belong to the $\mathrm{G}$ protein-coupled receptor family and are mainly expressed in hematopoietic and immune cells, such as B-cells, T-cells, and macrophages; thus, CB2R activation might be useful for treating cancers affecting plasma cells, such as multiple myeloma (MM). Previous studies have shown that CB2R stimulation may have anti-proliferative effects; therefore, the purpose of the present study was to explore the antitumor effect of beta-caryophyllene (BCP), a CB2R agonist, in an in vitro model of MM. Dexamethasone-resistant (MM.1R) and sensitive (MM.1S) human multiple myeloma cell lines were used in this study. Cells were treated with different concentrations of BCP for $24 \mathrm{~h}$, and a group of cells was pre-incubated with AM630, a specific CB2R antagonist. BCP treatment reduced cell proliferation through $\mathrm{CB} 2 \mathrm{R}$ stimulation; notably, $\mathrm{BCP}$ considerably increased the pro-apoptotic protein Bax and decreased the anti-apoptotic molecule Bcl-2. Furthermore, an increase in caspase 3 protein levels was detected following BCP incubation, thus demonstrating its anti-proliferative effect through apoptosis activation. In addition, BCP regulated AKT, Wnt1, and beta-catenin expression, showing that CB2R stimulation may decrease cancer cell proliferation by modulating Wnt/ $\beta$-catenin signaling. These effects were counteracted by AM630 co-incubation, thus confirming that $\mathrm{BCP}^{\prime} \mathrm{s}$ mechanism of action is mainly related to CB2R modulation. A decrease in $\beta$ catenin regulated the impaired cell cycle and especially promoted cyclin D1 and CDK 4/6 reduction. 
Taken together, these data revealed that BCP might have significant and effective anti-cancer and antiproliferative effects in MM cells by activating apoptosis, modulating different molecular pathways, and downregulating the cell cycle.

Keywords: beta-caryophyllene; cannabinoid receptor 2; multiple myeloma; apoptosis; Wnt/ $\beta$-catenin

\section{Introduction}

Multiple myeloma (MM) is a malignant B-cell neoplasm characterized by monoclonal plasma cell proliferation in the bone marrow. Among the hematologic tumors, $\mathrm{MM}$ is the second-most frequent malignancy worldwide, with over 30,000 cases of MM reported in the United States in 2019 [1]. One of the main hallmarks of MM is the uncontrolled proliferation of clonal plasma cells, which is responsible for its malignancy and possible invasion [2]. This uncontrolled proliferation is mainly due to the dysregulation of the cell cycle, which contributes to the progression of the disease and worsens the prognosis. Some patients may become refractory to the current therapies, which are mainly based on the use of proteasome inhibitors, bisphosphonates, corticosteroids, immunosuppressant drugs, and peripheral blood stem cell transplantation; for this reason, MM is still an incurable cancer [3], and various efforts are devoted to discovering new therapeutic approaches. In this context, previous studies have shown that cannabinoid type 2 receptors (CB2Rs) are highly expressed in B-cells, which are plasma cell (PCs) precursors, and in hematopoietic cells [4,5]. In addition, MM cell lines and primary MM cells highly express CB2Rs, suggesting significant expression of CB2Rs in B PCs as well [6]. Interestingly, some studies have indicated that immune cells are able to secrete 2-arachidonoyl glycerol (2-AG), an endocannabinoid that acts as an agonist of cannabinoid receptors [7-9]. Several studies have demonstrated the anti-cancer activity of cannabinoids [10-13], which is mainly ascribed to cell proliferation arrest, selective apoptosis induction, cell cycle modulation, and tumor growth inhibition $[14,15]$. In particular, a previous study demonstrated that cannabinoid derivatives are able to reduce the cell viability of the MM cell line and primary MPCs collected from high-risk MM patients; interestingly, this anti-proliferative effect was selective toward cancer cells and not normal healthy cells [10].

The high selectivity of cannabinoid derivatives assumes an important translational significance since the available chemotherapeutic agents are not specific to cancer cells and are responsible for a great number of adverse events.

Beta-caryophyllene ( $\beta$-caryophyllene, $\mathrm{BCP}$ ) is a non-psychoactive sesquiterpene extracted from Copaifera spp and Cannabis spp with significant antioxidant, anti-inflammatory, chemo-preventive, neuroprotective, and anti-proliferative effects [16-18]. BCP has been approved by the Food and Drug Administration (FDA) as a food additive, taste enhancer, and flavoring agent, and it could be used as a nutraceutical and a dietary supplement $[16,19]$. However, $\mathrm{BCP}$ is poorly aqueous-soluble and is sensitive to light, oxygen, humidity, and high temperatures; for this reason, its bioavailability may be affected, thus reducing its pharmacologic activity [20]. In fact, several delivery systems have been developed to overcome this significant limitation and improve both BCP stability and bioavailability [21-23] so that this promising compound could be used in future clinical practice.

$\mathrm{BCP}$ selectively binds CB2R [24,25], and as a result, it does not induce any psychoactive effects related to $\mathrm{CB} 1$ receptor binding. This mechanism of action is responsible for the pharmacological effects of $\mathrm{BCP}$, and its anti-cancer activity is mainly based on cell survival protein inhibition, cell cycle modulation, and apoptosis activation [13].

In the light of the cannabinoid's anti-cancer effects, evidenced by high CB2R expression in myeloma cells, the aim of this study was to evaluate the effects of BCP, a CB2R agonist, in dexamethasone-resistant (MM.1R) and sensitive (MM.1S) human MM cell lines. 


\section{Materials and Methods}

\subsection{Cell Cultures}

MM.1S (steroid-based therapy-resistant) and MM.1R (dexamethasone-resistant), human B lymphoblasts obtained from the peripheral blood of a patient affected by MM, were provided by ATCC ${ }^{\circledR}$ CRL-2974 ${ }^{\mathrm{TM}}$ and $\mathrm{ATCC}^{\circledR}{ }^{\circledR}$ CRL-2975 ${ }^{\mathrm{TM}}$ (ATCC Manassas, Manassas, VA, USA), respectively. Both cell cultures were plated in RPMI-1640 media (ATCC Manassas, Manassas, VA, USA) with $2 \mathrm{mM}$ L-glutamine, $1 \mathrm{mM}$ sodium pyruvate, $1 \%$ antibiotic mixture (Sigma-Aldrich, St. Louis, MO, USA), and 10\% fetal bovine serum (FBS) (ATCC Manassas, Manassas, VA, USA) in a humidified incubator at $37^{\circ} \mathrm{C}$ with a percentage of $5 \% \mathrm{CO}_{2}$. In addition, RPMI 1788 cells $\left(\mathrm{ATCC}^{\circledR}\right.$ CCL-156 ${ }^{\mathrm{TM}}$; ATCC Manassas, Manassas, VA, USA), which are human B lymphoblasts obtained from the peripheral blood of a healthy donor, were cultured in RPMI-1640 medium supplemented with 20\% FBS (ATCC Manassas, Manassas, VA, USA) and a 1\% antibiotic mixture (Sigma-Aldrich, St. Louis, MO, USA) in a humidified incubator at $37^{\circ} \mathrm{C}$ with a percentage of $5 \% \mathrm{CO}_{2}$.

\subsection{Cell Treatment}

MM.1S and MM.1R were placed in culture using 6-well plates with a density of $2.5 \times 10^{5}$ cells/well; cells were treated with BCP (Sigma-Aldrich, St. Louis, MO, USA; purity $>80 \%$ ) at concentrations of 50 and $100 \mu \mathrm{M}$ for $24 \mathrm{~h}$. At the end of BCP treatment, cells were collected to perform fluorescein diacetate/propidium iodide (FDA/PI) staining, molecular evaluations, and immunofluorescence. In addition, a group of MM.1S and MM.1R cells were treated with AM630 (Tocris Bioscience, Oxford, UK), a CB2 receptor antagonist, at a concentration of $100 \mathrm{nM} 2 \mathrm{~h}$ before BCP treatment.

\subsection{FDA/PI Staining}

FDA/PI staining (Sigma-Aldrich, St. Louis, MO, USA) was used to evaluate MM.1S and MM.1R cell viability. FDA stock solution was prepared by dissolving $5 \mathrm{mg}$ of FDA in $1 \mathrm{~mL}$ of acetone, and a PI stock solution was prepared by dissolving $2 \mathrm{mg}$ of PI in $1 \mathrm{~mL}$ of phosphate-buffered saline (PBS). The FDA/PI staining solution was prepared by adding $8 \mu \mathrm{L}$ of FDA $(5 \mathrm{mg} / \mathrm{mL})$ and $50 \mu \mathrm{L}$ of PI $(2 \mathrm{mg} / \mathrm{mL})$ in $5 \mathrm{~mL}$ of culture medium without FBS. Cells were seeded at a density of $5 \times 10^{5}$ cells/well in a 24 -well plate and treated with 50 and $100 \mu \mathrm{M}$ BCP. The culture medium was removed after $24 \mathrm{~h}$, and cells were stained with the FDA/PI staining solution for $5 \mathrm{~min}$ at room temperature in the dark. Viable cells were observed with a fluorescence microscope. The quantification of positive cells was performed with ImageJ software for Windows (Softonic, Barcelona, Spain).

\subsection{MTT Assay}

An MTT assay was carried out to evaluate cancer cell viability following BCP treatment. MM.1S, MM.1R, and RPMI 1788 were seeded in a 96-well plate at a density of $2 \times 10^{5}$ cells $/$ well for $24 \mathrm{~h}$. The day after, cells were treated with doubling concentrations of $\operatorname{BCP}(6.25,12.5,25,50,100$, and $200 \mu \mathrm{M})$ for $24 \mathrm{~h}$ in order to evaluate the cytotoxic effect, as previously described [25].

\subsection{Trypan Blue Assay}

Trypan blue dye was used to quantify the comparative number of live and dead cells. Cells were collected and centrifuged at $1200 \mathrm{rpm}$ for $5 \mathrm{~min}$. The obtained cell pellets were resuspended in $1 \mathrm{~mL}$ of fresh medium. The suspension and a $0.4 \%$ trypan blue/PBS solution were mixed in a 1:1 ratio. Ten microliters of this mixture was loaded on a hemocytometer and visualized with an optical microscope. The percent viability was determined using the following formula:

$$
\% \text { viable cells }=[1.00-(\text { Number of blue cells } \div \text { Number of total cells })] \times 100
$$




\subsection{Measurements of Proteins by Enzyme-Linked Immunosorbent Assay (ELISA)}

CDK4, CDK6, and Wnt1 levels were evaluated in the cell lysates, using the respective enzyme-linked immunosorbent assay (ELISA) kits (LSBio, Seattle, WA, USA, or MyBioSource, San Diego, CA, USA), following the instructions reported by the manufacturer [26].

\subsection{Western Blot Analysis}

After $24 \mathrm{~h}$ of BCP treatment, cells were collected, and the protein expressions of phospho- $\beta$-catenin, phospho-Akt, Bax, caspase-3 (Cell Signaling, Danvers, MA, USA), cyclin D1 (Gentex, Irvine, CA, USA), and Bcl-2 (Abcam, Cambridge, UK) were evaluated, as previously described in detail $[27,28]$.

\subsection{Immunofluorescence Staining}

MM.1S and MM.1R were seeded onto glass coverslips, processed for immunofluorescence following $24 \mathrm{~h}$ of $\mathrm{BCP}$ treatment, and photographed according to the techniques previously described in detail [29].

\subsection{Statistical Analysis}

All results are expressed as means \pm standard error of the mean (SEM). The reported results are the means of three experiments. In order to guarantee reproducibility, all assays were performed in duplicate. Statistical analysis was conducted using one-way ANOVA with Tukey's post hoc test for intergroup comparisons. A $p$-value less than 0.05 was considered significant. Graphs were prepared using GraphPad Prism software (Version 8.0 for macOS, San Diego, CA, USA).

\section{Results}

\subsection{BCP Reduces Cancer Cells Viability}

Cell viability was evaluated by incubating MM.1S, MM.1R, and RPMI 1788 cell lines with increasing concentrations of $\mathrm{BCP}$, ranging from $6.25 \mu \mathrm{M}$ to $200 \mu \mathrm{M}$. The results of the MTT assay showed that MM.1R cell viability was reduced when cells were treated with $\mathrm{BCP}$ at concentrations of $25 \mu \mathrm{M}$ to $200 \mu \mathrm{M}$; in particular, cell viability was reduced to about $80 \%$ when $\mathrm{BCP}$ was used at a concentration of $50 \mu \mathrm{M}$ and to $50 \%$ with $100 \mu \mathrm{M} \mathrm{BCP}$ following $24 \mathrm{~h}$ of treatment (Figure 1A). As shown in Figure 1B, reductions in cell viability of about $70 \%$ and $50 \%$ were observed when MM.1S cells were treated with 50 and $100 \mu \mathrm{M}$ $\mathrm{BCP}$, respectively. Moreover, BCP treatment did not affect the cell viability of RPMI1788 cells, demonstrating its selective antiproliferative effect on MM cells (Figure 1C).

A

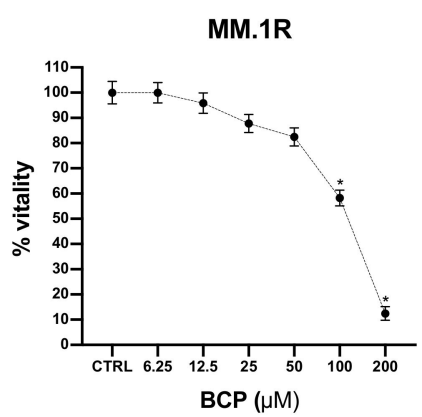

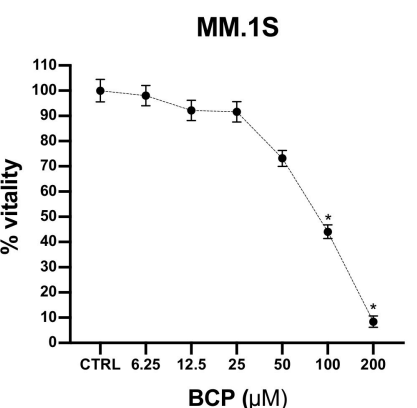

$\mathrm{C}$

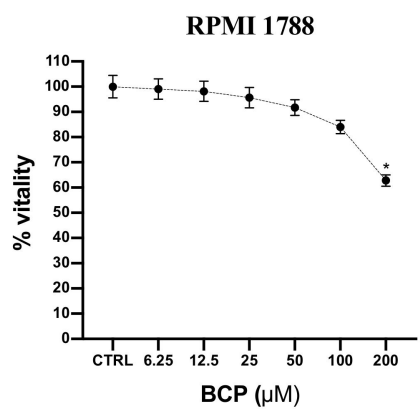

Figure 1. Cell viability evaluated in MM.1R (A), MM.1S (B), and RPMI 1788 (C) cell lines treated with BCP using MTT assays. Values are expressed as percentages of viability reduction compared with control cells. The data are expressed as means $\pm \mathrm{SEM} ; n=3$ experiments; ${ }^{*} p<0.05$ vs. Ctrl.

Images obtained from the FDA/PI staining also showed cell viability: live cells were bright green and nonviable cells were red. Notably, untreated MM.1S cells stained with 
FDA showed bright fluorescence, but a low level of fluorescence was observed with PI labeling; MM.1R cells treated with BCP at concentrations of 50 and $100 \mu \mathrm{M}$ for $24 \mathrm{~h}$ showed few cells stained with FDA but many nuclei stained with PI (Figure 2A-F). Overlapping results were obtained in the MM.1S cell line (Figure 2G-N). The graphs presented in Figure $2 \mathrm{O}, \mathrm{P}$ represent the cell counts of MM.1R and MM.1S positive cells. BCP at a concentration of $50 \mu \mathrm{M}$ increased the number of PI-positive cells in both cell lines $(p<0.05$ vs. CTRL) and reduced the number of positive FDA cells only in MM.1S cells $(p<0.05$ vs. CTRL). BCP at a concentration of $100 \mu \mathrm{M}$ significantly increased the number of PI-positive cells ( $p<0.0001$ vs. CTRL) and strongly reduced the number of FDA-positive cells in both cell lines $(p<0.05$ vs. CTRL).
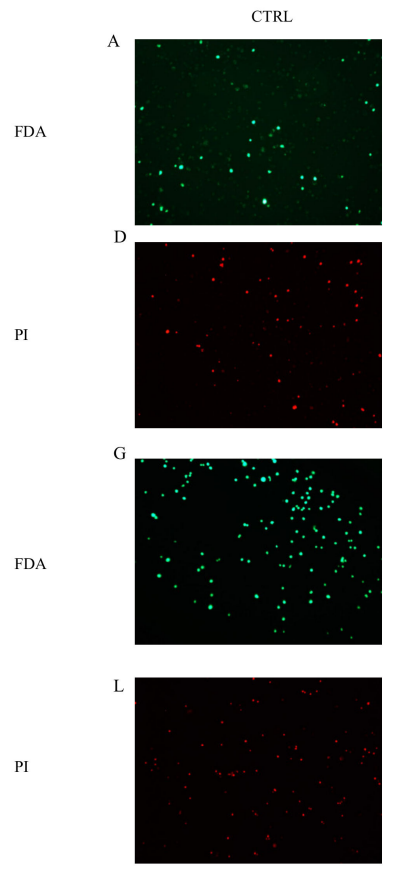
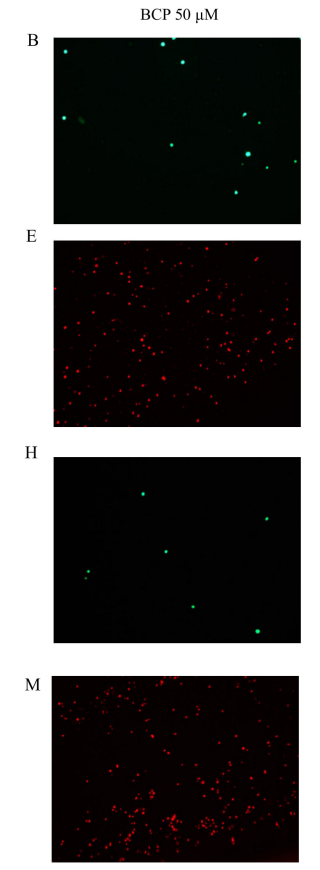
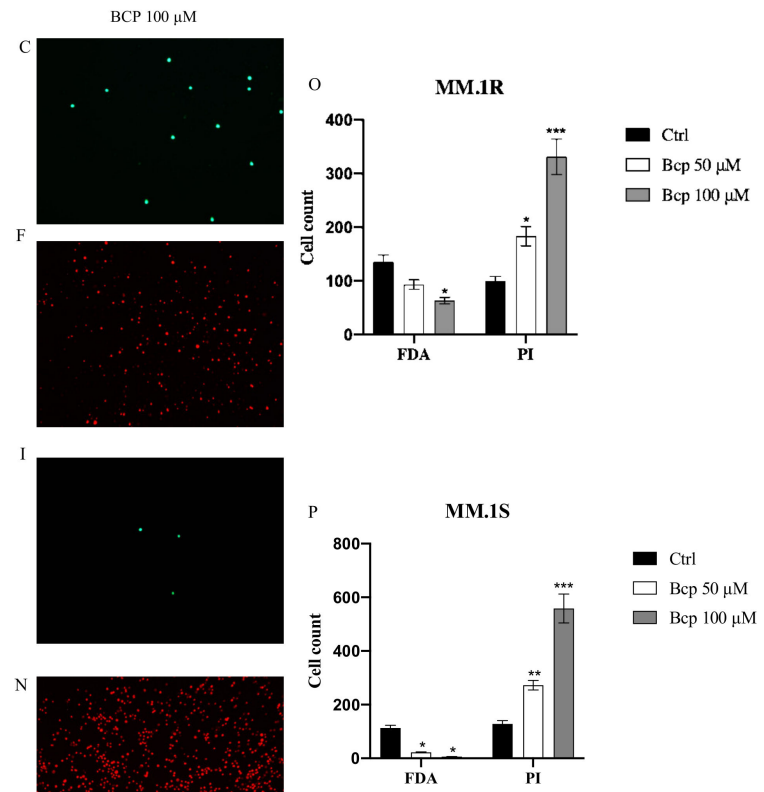

Figure 2. The figure represents the apoptotic process evaluated by FDA/PI staining in MM.1R and MM.1S cell lines treated with BCP. In panels (A-C) and (G-I), green color reaction indicates viable MM.1R and MM.1S cells, respectively; in panels (D-F) and (L-N), red reaction indicates MM.1R and MM.1S cells that underwent apoptosis, respectively. Panels $(\mathbf{O})$ and $(\mathbf{P})$ show the cells counts in MM.1R and MM.1S. The data are expressed as means \pm SEM; $n=3$ experiments; ${ }^{*} p<0.05$ vs. Ctrl. ** $p<0.001$ vs. Ctrl. ${ }^{* *} p<0.0001$ vs. Ctrl.

In addition, a trypan blue assay was performed to confirm the selective antiproliferative effect of BCP on the MM.1S and MM.1R cell lines. The RPMI 1788 cell line, used as normal cells, was treated with BCP at concentrations of 50 and $100 \mu \mathrm{M}$ for $24 \mathrm{~h}$, thus demonstrating that BCP did not affect the proliferation of normal cells (Figure 3) and confirming the MTT results and BCP-selective effect in the MM cell lines.

A

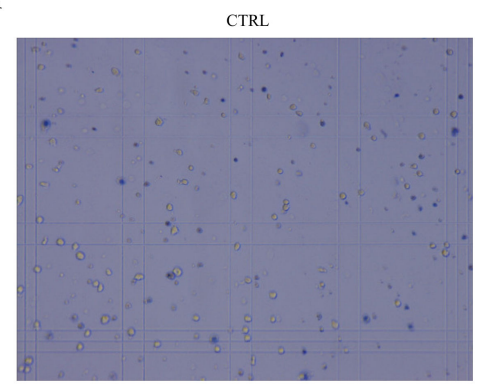

B

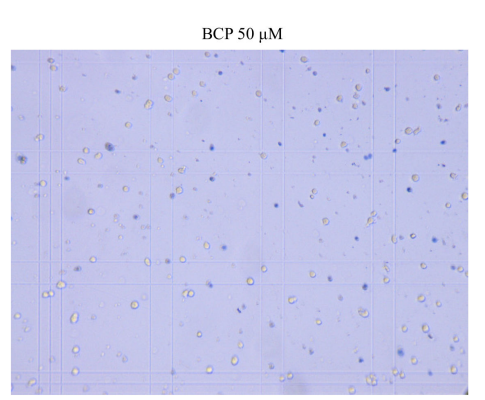

C

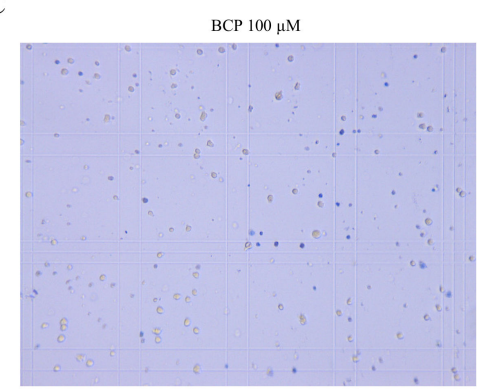

Figure 3. Cont. 
$\mathrm{D}$

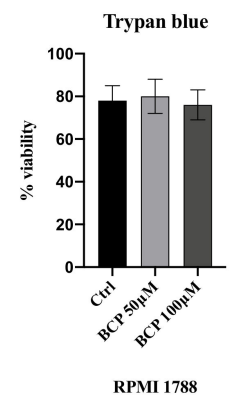

Figure 3. The figure represents the trypan blue staining in RPMI 1788 cells treated with BCP. In panels (A-C), blue color reaction indicates RPMI 1788 cells that underwent apoptosis. Panel (D) shows the percentage of viable cells. The data are expressed as means $\pm \mathrm{SEM} ; n=3$ experiments.

\subsection{BCP Treatment Induces Apoptotic Pathways in MM.1S and MM.1R Cell Lines}

Bcl-2, Bax, and caspase-3 protein expression were studied using Western blot analysis to evaluate whether BCP induces the apoptotic pathway in MM.1S (Figure 4A-C, Figure S1) and MM.1R (Figure 4D-F, Figure S1) cancer cells. BCP significantly increased caspase-3 and Bax, whereas it reduced Bcl-2 expression, compared with untreated cells in both MM.1S and MM.1R following $24 \mathrm{~h}$ of treatment especially at a concentration of $100 \mu \mathrm{M}$, thus indicating that BCP induced the apoptotic process in MM cancer cells ( $p<0.05$ vs. CTRL; Figure 4 ).

A

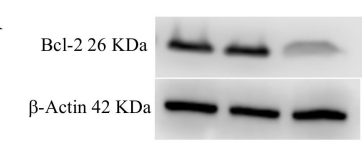

Bcl-2

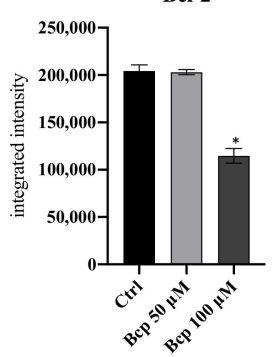

$\mathrm{D}$
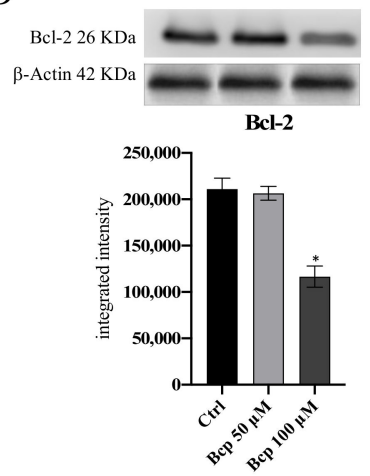

B
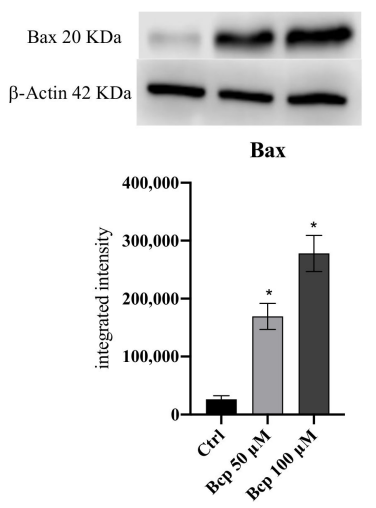

$\mathrm{E}$

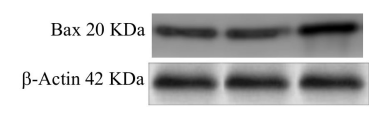

Bax

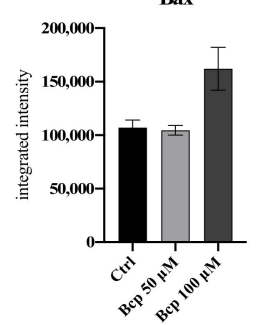

$\mathrm{C}$

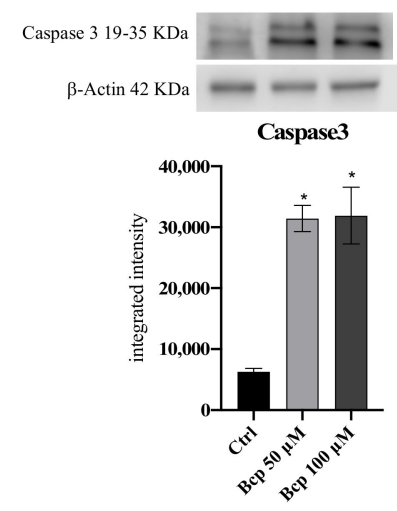

$\mathrm{F}$
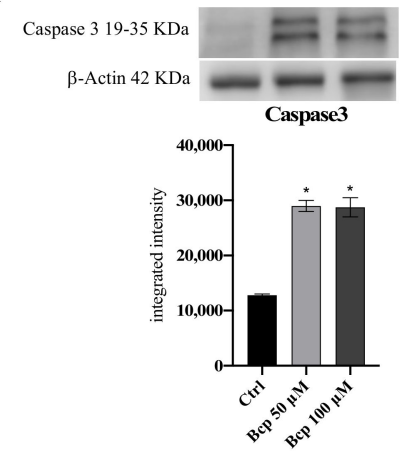

Figure 4. The graphs represent Bcl-2 (A), Bax (B), and caspase 3 (C) protein expression in MM.1S cells and protein expression of Bcl-2 (D), Bax (E), and caspase3 (F) in MM.1R cells treated with BCP. The data are expressed as means \pm SEM; $n=3$ experiments; $* p<0.05$ vs. Ctrl. 


\subsection{BCP Has a Significant Anti-Proliferative Effect through Akt and Wnt/ $\beta$-Catenin Modulation}

Wnt1 protein levels as well as p-Akt and $\beta$-catenin protein expression were evaluated to investigate BCP's anti-proliferative effects in MM.1S and MM.1R cancer cells. BCP treatment caused a marked reduction in Wnt1 in the MM.1S cell line $(p<0.05$ vs. CTRL; Figure 5), particularly at a concentration of $100 \mu \mathrm{M}$. Similar results were obtained in the MM.1R cancer cell line: BCP significantly reduced Wnt1 following $24 \mathrm{~h}$ of treatment compared with untreated cells ( $p<0.05$ vs. CTRL; Figure 5). In addition, both cell lines treated with $\mathrm{BCP}$ at a concentration of $100 \mu \mathrm{M}$ showed a significant decrease in p-Akt and $\beta$-catenin protein expression, confirming that $\mathrm{BCP}$ treatment may have an anti-proliferative effect through Wnt1, p-Akt, and $\beta$-catenin reduction $(p<0.05$ vs. CTRL; Figure 5 and Figures S2-S5). Wnt1, p-Akt, and $\beta$-catenin reduction was reversed by the treatment with the CB2R antagonist AM630, which abrogated BCP's effects, thus demonstrating that BCP's mechanism of action was related to CB2 receptor modulation.

A

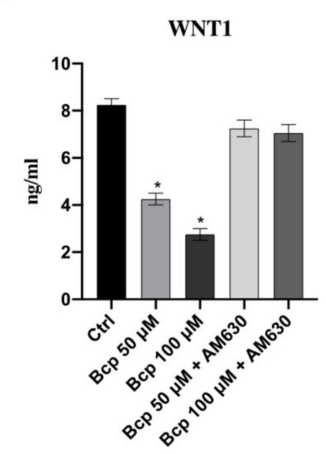

$\mathrm{D}$

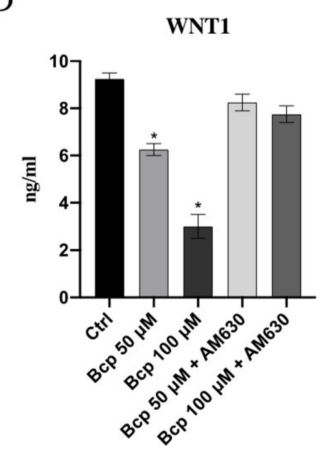

B

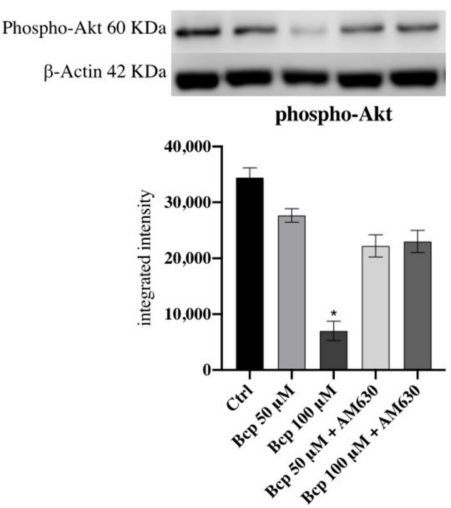

$\mathrm{E}$

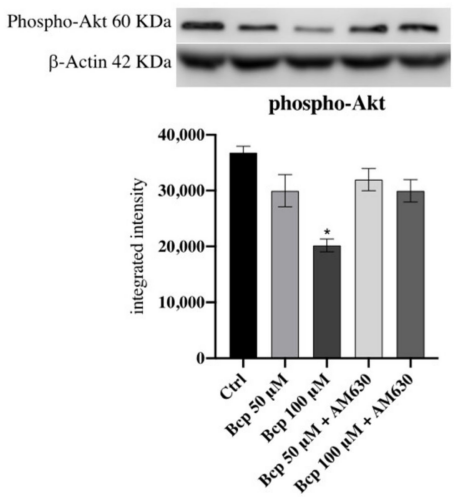

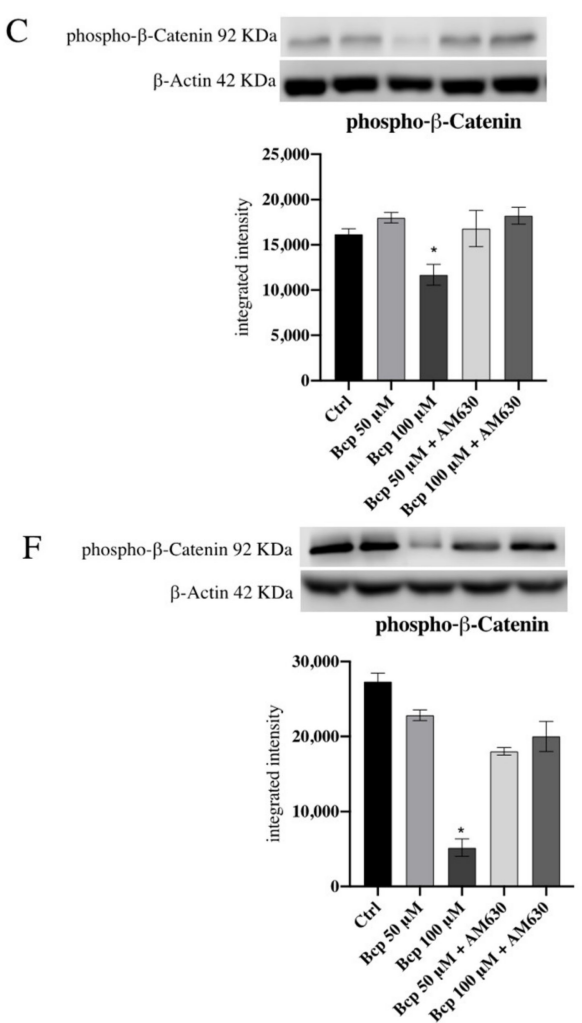

Figure 5. The graphs represent protein levels of Wnt1 (A), p-Akt (B), and p- $\beta$-Catenin (C) in MM.1S cells and Wnt1 (D), $\mathrm{p}$-Akt $(\mathbf{E})$, and $\mathrm{p}-\beta$-Catenin $(\mathbf{F})$ protein levels in MM.1R cells treated with BCP. The data are expressed as means \pm SEM; $n=3$ experiments; $*<<0.05$ vs. Ctrl.

The reduction in $\beta$-catenin activation following BCP treatment was also observed in immunofluorescence. Control cells showed positive staining for $\beta$-catenin; this staining pattern was appreciable around the nuclei and at the plasma membrane level (Figure 6A,B). The images in Figure 6C (Figure S6) and D show a very low $\beta$-catenin staining pattern, thus confirming $\mathrm{BCP}^{\prime}$ s efficacy in reducing $\beta$-catenin activation. 


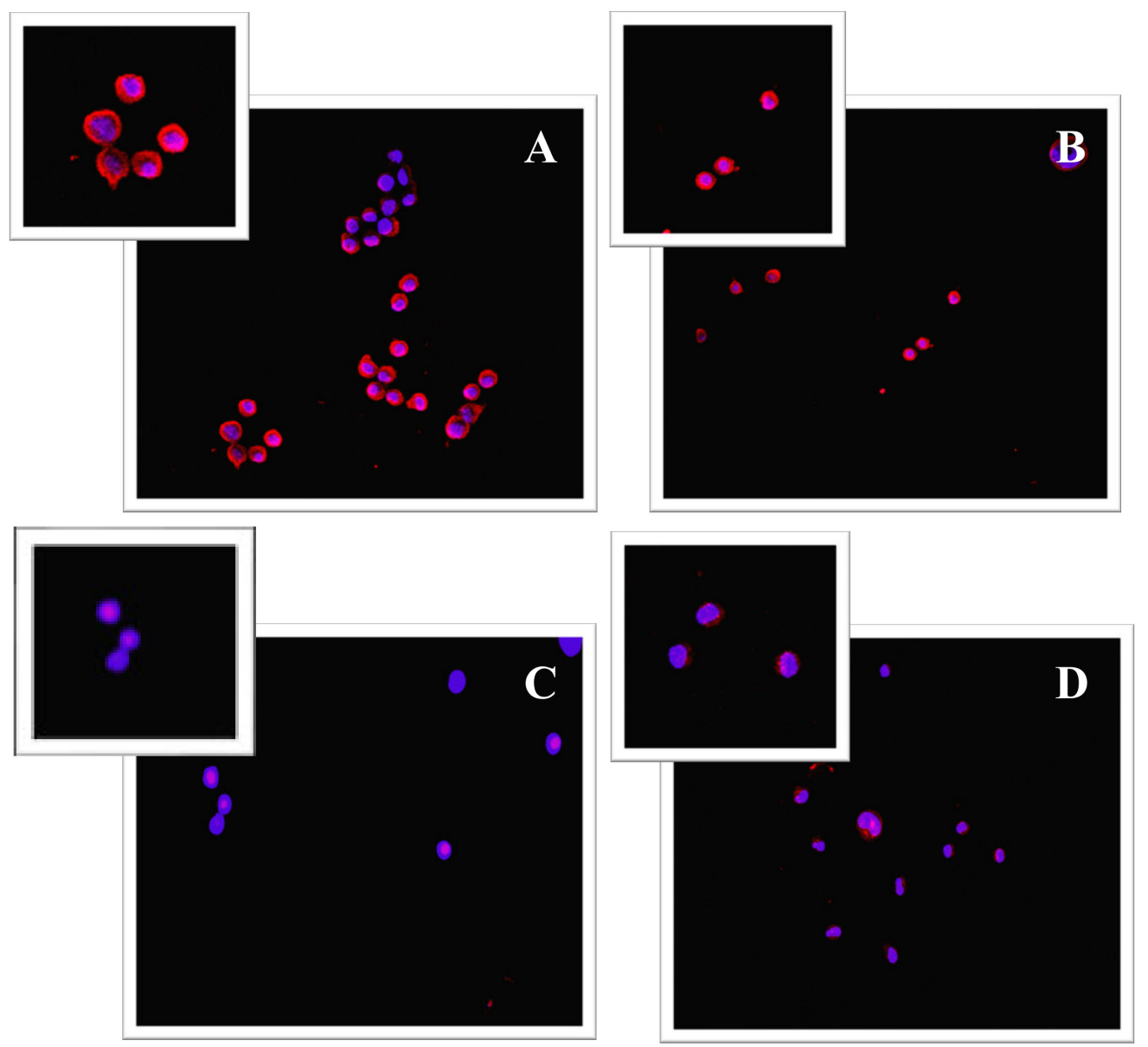

Figure 6. Panel of immunofluorescence staining for $\beta$-catenin (red fluorescence). $\beta$-catenin fluorescence pattern in control cells, MM.1S (A), and MM.1R (B) is mainly distributed at the perinuclear and plasma membrane level, as clearly shown in the magnifications in the left corners; MM.1 S cells treated with $\mathrm{BCP}$ for $24 \mathrm{~h}$ showed a strong reduction in $\beta$-catenin staining (C); BCP treatment for $24 \mathrm{~h}$ caused a significant $\beta$-catenin fluorescence reduction in MM.1R treated cells (D).

\subsection{BCP Anti-Proliferative Effect Is Carried out through Cell Cycle Inhibition}

The hypothesis that BCP might exert an anti-proliferative effect in MM cancer cells was further confirmed by the results obtained for cyclin D1 expression and the levels of its kinases, CDK 4 and 6. BCP treatment, particularly at a concentration of $100 \mu \mathrm{M}$, significantly reduced CDK4 and CDK6 levels both in MM.1S and MM.1R cells compared with untreated cells ( $p<0.05$ vs. CTRL; Figure 7). As expected, cyclin D1 protein expression was downregulated when MM.1S and MM.1R cells were treated with BCP at a concentration of $100 \mu \mathrm{M}$ following $24 \mathrm{~h}$ of treatment ( $p<0.05$ vs. CTRL; Figure 7 and Figures S6 and S7). 
A

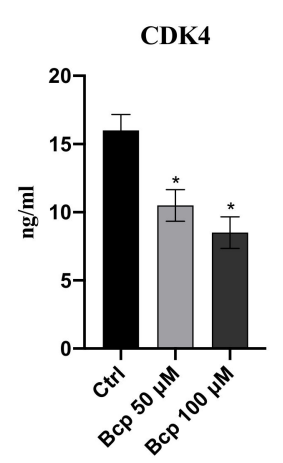

$\mathrm{D}$

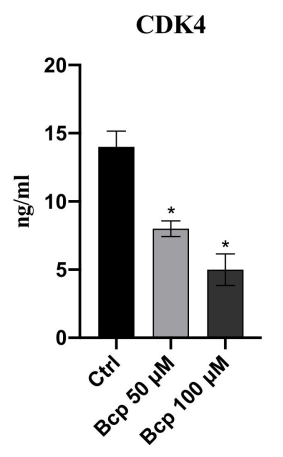

B

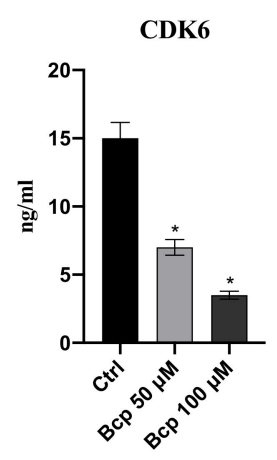

$\mathrm{E}$

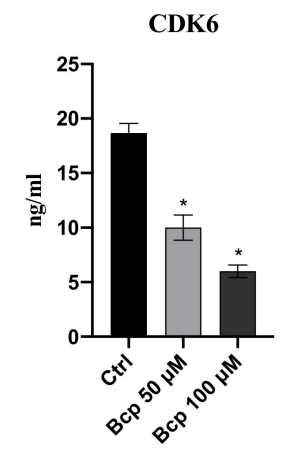

C

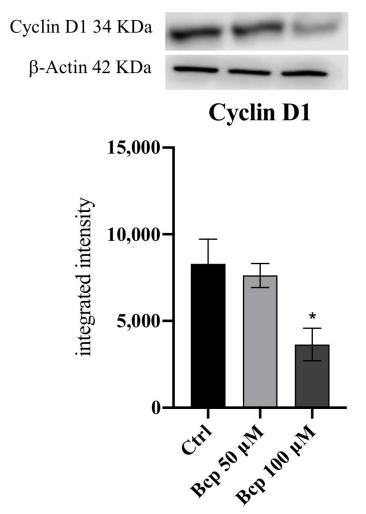

F

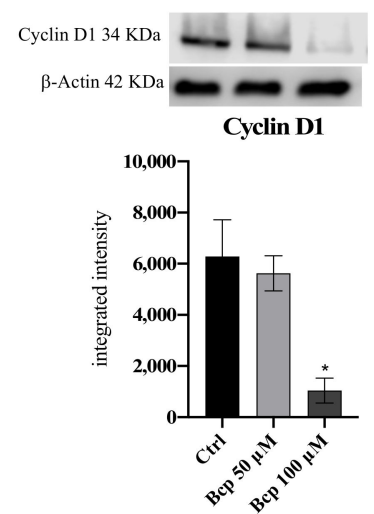

Figure 7. The graphs represent CDK4 (A), CDK6 (B), and cyclin D1 (C) protein levels in MM.1S cells. CDK4 (D), CDK6 (E), and cyclin D1 (F) protein levels in MM.1R cells treated with BCP. The data are expressed as means \pm SEM; $n=3$ experiments; * $p<0.05$ vs. Ctrl.

\section{Discussion}

In the past years, several efforts have been made by the scientific community to characterize the role of the ECS in several body areas and to understand if cannabinoid receptors might be considered as effective therapeutic targets. The use of the cannabis plant and its derivatives might represent a new therapeutic window for the management of diseases for which there is no effective therapy, such as cancers, and have a significant impact on medicine and the global economy. Cannabinoids have shown anti-emetic effects in cancer patients as well as significant anti-neoplastic effects in solid tumors, such as glioma and breast cancer [30-32]. The exact mechanism of action is not completely understood, but the therapeutic approach is mainly based on the wide distribution of cannabinoid receptors. MM cells express cannabinoid receptors, as demonstrated by flow cytometry analysis [10,33], and experimental studies have demonstrated that both cannabidiol and different cannabinoid derivatives induce apoptosis in MM cell lines through a caspasedependent mechanism $[7,10]$.

In the present experimental setting, $\mathrm{BCP}$, a natural $\mathrm{CB} 2 \mathrm{R}$ agonist, was evaluated for its anti-proliferative and anti-neoplastic effects in MM.1S and MM.1R cells; in particular, MM.1R cells respond less to chemotherapy and represent a condition observed in cancer patients in advanced stages of the disease [34]. Our team already revealed that BCP reduced cell viability in glioma cell lines and glioma-derived stem-like cells, thus demonstrating that BCP might be used in conditions of resistance [13]. BCP is a safe compound; in fact, it did not affect healthy cells, such as human gingival fibroblasts and human oral mucosa epithelial cells, as already demonstrated in our previous study [25]; in addition, another CB2 agonist, WIN-55,212-2 mesylate, was not only effective in reducing cancer cells proliferation but was also selective toward cancer cells and not control cells (healthy cells) [10], thus supporting the hypothesis that $\mathrm{BCP}$ might be used in the clinical practice, affecting cancer cells and remaining safe for normal cells. In accordance with our experimental hypothesis, 
it has been previously confirmed that cannabinoid use may selectively stimulate apoptosis in MM cells through a caspase-2-dependent mechanism, but what is even more interesting is that cell death was only activated in MM cells and did not affect normal cells; moreover, cannabinoid-induced apoptosis was inhibited by blocking CB2R $[10,33]$.

$\mathrm{BCP}$ also proved effective in MM.1S cells and the more resistant MM.1R cell line at concentrations of $50 \mu \mathrm{M}$ and $100 \mu \mathrm{M}$, thus reducing the cell viability of cancer cells and not affecting normal cells, as demonstrated by the MTT assay and trypan blue staining; in particular, the fluorescent marking with FDA confirmed the MTT results and demonstrated that BCP significantly reduced the number of viable cells. This antiproliferative effect is mainly due to the activation of apoptosis as a cell death mechanism. In fact, the triggering of Bax and caspase- 3 following BCP treatment in both cell lines pointed out that $\mathrm{BCP}$ anti-neoplastic activity might be ascribed to a caspase-dependent mechanism of cell death and p53-mediated apoptosis through Bax stimulation. In addition, Bcl-2, which usually promotes cell survival and is considered an anti-apoptotic protein [35], was significantly reduced in treated cancer cells in favor of apoptotic markers, thus confirming BCP's proapoptotic effect. Cannabinoids were able to induce apoptosis in melanoma, glioma, breast cancer, and MM cells through a molecular mechanism that provides for Akt modulation, which is one of the most strongly involved pathways in response to cannabinoid receptor stimulation $[15,36]$.

Phosphatidylinositol-3-kinase (PI3K)/Akt and the mammalian target of rapamycin (mTOR) signaling pathway, which controls cell proliferation, is abnormally activated in several cancers and also in MM patients [37]; therefore, a drug that inhibits this pathway might be effective in the treatment of MM. BCP treatment markedly reduced Akt expression, particularly at a concentration of $100 \mu \mathrm{M}$, in both cell lines compared with untreated cells, thus providing an important translational relevance since Akt overexpression often correlates with poor outcomes [38]. PI3K/Akt/mTOR is a sophisticated pathway that is interconnected with other signaling pathways, such as Wnt/ $\beta$-catenin signaling. $W n t / \beta$-catenin pathway activation is involved in both normal development and aberrant cell proliferation; in fact, a $\beta$-catenin increase may exert oncogenic effects in different tumors $[39,40]$. BCP's anti-proliferative effect was established by the results obtained from Wnt 1 and $\beta$-catenin expression: a significant decrease was observed in the treated MM.1R and MM.1S cell lines compared with untreated cancer cells. These anti-proliferative effects were abrogated when MM.1 cells were treated with both BCP and the CB2R antagonist AM630, thus demonstrating that $B C P^{\prime}$ 's mechanism of action is strictly related to $C B 2 R$ modulation since AM630 antagonizes this specific receptor. MM.1 cells treated with BCP showed a significant reduction of the positive fluorescence of $\beta$-catenin compared with controls (tumor cells). These data indicate that $\mathrm{BCP}^{\prime} \mathrm{s}$ anti-proliferative effect may be due to the complex modulation of the Akt and Wnt/ $\beta$-catenin pathways through the essential stimulation of the apoptotic mechanism.

The cyclin D1 gene is a target for $\beta$-catenin and is accountable for the progression of cells into the proliferative stage of the cell cycle [41]. In fact, $\beta$-catenin-mediated signaling depends on its accumulation and consequent translocation into the nucleus, where it regulates gene transcription. Increased $\beta$-catenin levels were associated with malignancies, and this increase is considered one of the features of MM, thus promoting tumor progression through cell cycle activation [42]. The cell cycle is a process that is regulated by different cyclins and their CDKs; the likelihood of developing cancer dramatically increases when the precise balance between cyclins and CDKs is impaired [43]. One of the main alterations observed in cancer concerns cyclin D and CDK4/ 6 overexpression, and in particular, cyclin $\mathrm{D}$ alteration is one of the key hallmarks of MM $[44,45]$. For this reason, targeting these cell cycle regulators may represent a promising therapeutic approach for the management of myeloma. Surprisingly, in our experimental model, we observed that BCP treatment induced the reduction of cyclin D1 and its kinases, CDK4 and CDK6, in both the MM.1S and MM.1R cell lines compared with untreated cells, further demonstrating BPC's anti- 
proliferative effects through cell cycle modulation, probably as a consequence of $\beta$-catenin reduction (Figure 8).

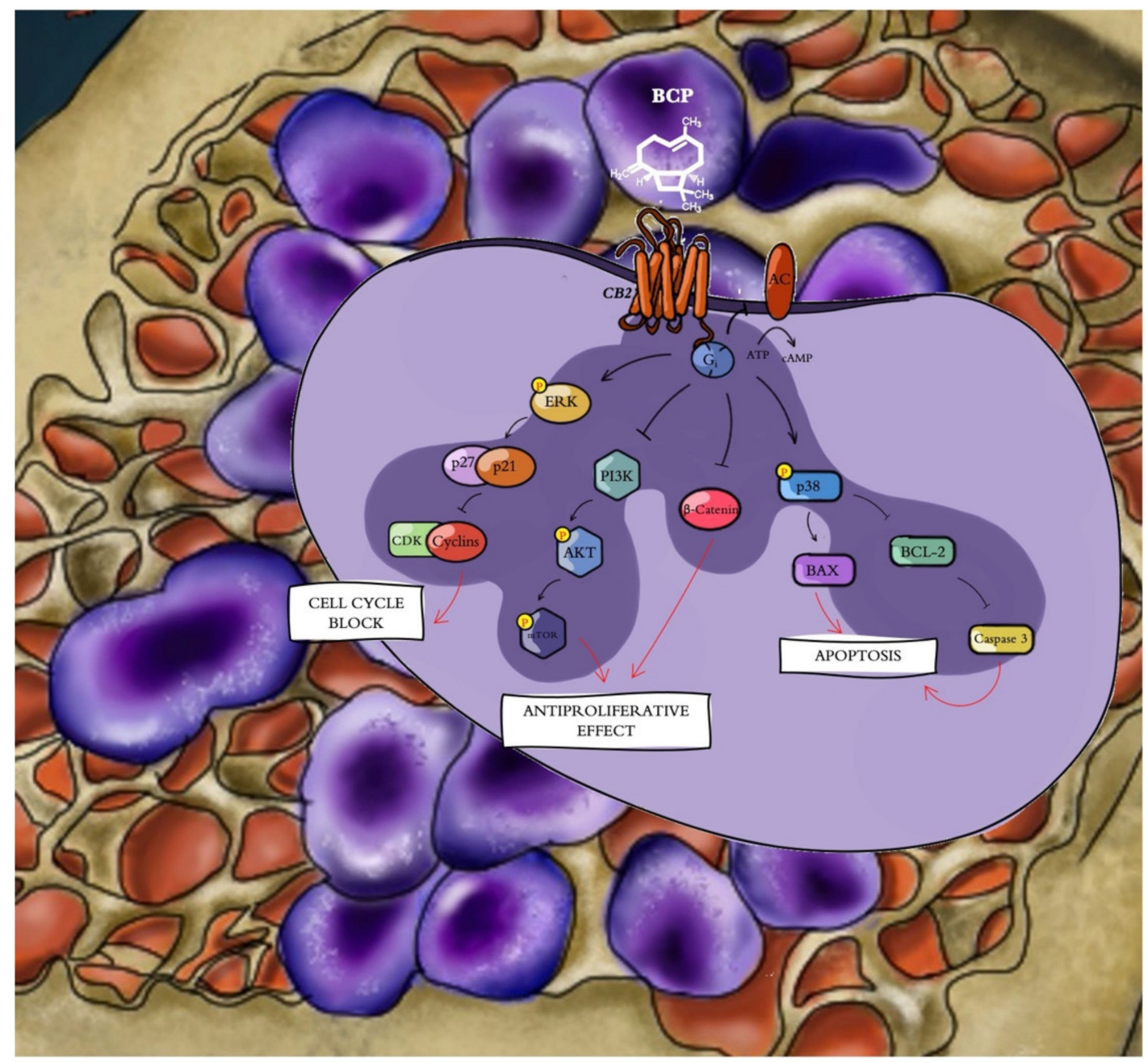

Figure 8. Beta-caryophyllene ( $\beta$-caryophyllene, $\mathrm{BCP}$ ) selectively binds cannabinoid type 2 receptor (CB2R), thus inducing an antiproliferative effect through (i) cell cycle modulation by reducing cyclin D1 and Cdk 4/6 expression, (ii) apoptosis activation by increasing Bax and caspase 3 and reducing Bcl-2 expression, and (iii) Akt and $\beta$-catenin inhibition.

\section{Conclusions}

MM is considered an incurable plasma cell cancer; blocking cell proliferation and consequently cell progression in terms of invasion may represent an interesting approach to improve anti-myeloma therapy. On one hand, BCP was able to induce the apoptotic mechanism, activating the molecules involved in apoptosis; moreover, $\mathrm{BCP}$ regulated cell proliferation through sophisticated crosstalk between Akt, $\beta$-catenin, and cyclin D/CDK $4 / 6$ in a concentration-dependent manner. However, in vivo experimental approaches should be developed to confirm the results described so far and demonstrate that BCP might represent an interesting alternative or additional therapeutic approach to conventional chemotherapy for the treatment of multiple myeloma.

Supplementary Materials: The following are available online at https:/ /www.mdpi.com/article/10 .3390/cancers13225741/s1, Figure S1: Original western blots for Figure 4A-F, Figure S2: Original Western blots for Figure 5B, Figure S3: Original Western blots for Figure 5C, Figure S4: Original Western blots for Figure 5E, Figure S5: Original Western blots for Figure 5F, Figure S6: Original Western blots for Figure 7C, Figure S7: Original figure blots for Figure 7F. 
Author Contributions: Conceptualization, F.M. and G.P.; formal analysis, R.C.; funding acquisition, F.S.; methodology, L.M. and D.A.; supervision, N.I.; validation, G.V., A.A., and A.H.E.; writingoriginal draft, F.M.; writing-review and editing, A.B. and F.S. All authors have read and agreed to the published version of the manuscript.

Funding: This work was supported by departmental funding provided to Francesco Squadrito.

Institutional Review Board Statement: Not applicable.

Informed Consent Statement: Not applicable.

Data Availability Statement: The datasets generated for this study are available on request to the corresponding author.

Acknowledgments: The authors would like to thank Rita Lauro for the brilliant graphic contribution to the cartoon-type figure in the present study.

Conflicts of Interest: The authors declare no conflict of interest.

\section{References}

1. Siegel, R.L.; Miller, K.D.; Jemal, A. Cancer statistics. CA Cancer J. Clin. 2019, 69, 7-34. [CrossRef]

2. Kuehl, W.M.; Bergsagel, P.L. Molecular pathogenesis of multiple myeloma and its premalignant precursor. J. Clin. Investig. 2012, 122, 3456-3463. [CrossRef]

3. Bianchi, G.; Anderson, K.C. Understanding biology to tackle the disease: Multiple myeloma from bench to bedside, and back. $C A$ Cancer J. Clin. 2014, 64, 422-444. [CrossRef]

4. Khodadadi, L.; Cheng, Q.; Radbruch, A.; Hiepe, F. The Maintenance of Memory Plasma Cells. Front. Immunol. 2019, 10, 721. [CrossRef]

5. Galiègue, S.; Mary, S.; Marchand, J.; Dussossoy, D.; Carrière, D.; Carayon, P.; Bouaboula, M.; Shire, D.; Le Fur, G.; Casellas, P. Expression of central and peripheral cannabinoid receptors in human immune tissues and leukocyte subpopulations. Eur. J. Biochem. 1995, 232, 54-61. [CrossRef]

6. Xie, X.-Q.; Feng, R.; Yang, P. Novel Cannabinoid Receptor 2 (CB2) Inverse Agonists and Therapeutic Potential for Multiple Myeloma and Osteoporosis Bone Diseases. US Patent 61/576,041, 15 December 2012.

7. Feng, R.; Tong, Q.; Xie, Z.; Cheng, H.; Wang, L.; Lentzsch, S.; Roodman, G.D.; Xie, X.Q. Targeting cannabinoid receptor-2 pathway by phenylacetylamide suppresses the proliferation of human myeloma cells through mitotic dysregulation and cytoskeleton disruption. Mol. Carcinog. 2015, 54, 1796-1806. [CrossRef]

8. Jordà, M.A.; Verbakel, S.E.; Valk, P.J.; Vankan-Berkhoudt, Y.V.; Maccarrone, M.; Finazzi-Agrò, A.; Löwenberg, B.; Delwel, R. Hematopoietic cells expressing the peripheral cannabinoid receptor migrate in response to the endocannabinoid 2-arachidonoylglycerol. Blood 2002, 99, 2786-2793. [CrossRef] [PubMed]

9. Tam, J.; Ofek, O.; Fride, E.; Ledent, C.; Gabet, Y.; Müller, R.; Zimmer, A.; Mackie, K.; Mechoulam, R.; Shohami, E.; et al. Involvement of neuronal cannabinoid receptor CB1 in regulation of bone mass and bone remodeling. Mol. Pharmacol. 2006, 70, 786-792. [CrossRef] [PubMed]

10. Barbado, M.V.; Medrano, M.; Caballero-Velázquez, T.; Álvarez-Laderas, I.; Sánchez-Abarca, L.I.; García-Guerrero, E.; MartínSánchez, J.; Rosado, I.V.; Piruat, J.I.; Gonzalez-Naranjo, P.; et al. Cannabinoid derivatives exert a potent anti-myeloma activity both in vitro and in vivo. Int. J. Cancer 2017, 1403, 674-685. [CrossRef] [PubMed]

11. Hashiesh, H.M.; Sharma, C.; Goyal, S.N.; Sadek, B.; Jha, N.K.; Kaabi, J.A.; Ojha, S. A focused review on CB2 receptor-selective pharmacological properties and therapeutic potential of $\beta$-caryophyllene, a dietary cannabinoid. Biomed Pharmacother. 2021, 140, 111639. [CrossRef]

12. Di Sotto, A.; Mancinelli, R.; Gullì, M.; Eufemi, M.; Mammolam, C.L.; Mazzanti, G.; Di Giacomo, S. Chemopreventive Potential of Caryophyllane Sesquiterpenes: An Overview of Preliminary Evidence. Cancers 2020, 12, 3034. [CrossRef] [PubMed]

13. Irrera, N.; D'Ascola, A.; Pallio, G.; Bitto, A.; Mannino, F.; Arcoraci, V.; Rottura, M.; Ieni, A.; Minutoli, L.; Metro, D.; et al. $\beta$-Caryophyllene Inhibits Cell Proliferation through a Direct Modulation of CB2 Receptors in Glioblastoma Cells. Cancers 2020, 12, 1038. [CrossRef]

14. Ellert-Miklaszewska, A.; Kaminska, B.; Konarska, L. Cannabinoids down-regulate PI3K/Akt and Erk signalling pathways and activate proapoptotic function of Bad protein. Cell Signal. 2005, 17, 25-37. [CrossRef]

15. Velasco, G.; Sanchez, C.; Guzman, M. Anticancer mechanisms of cannabinoids. Curr. Oncol. 2016, 23, S23-S32. [CrossRef] [PubMed]

16. Sharma, C.; Al Kaabi, J.M.; Nurulain, S.M.; Goyal, S.N.; Kamal, M.A.; Ojha, S. Polypharmacological Properties and Therapeutic Potential of $\beta$-Caryophyllene: A Dietary Phytocannabinoid of Pharmaceutical Promise. Curr. Pharm. Des. 2016, 22, $3237-3264$. [CrossRef]

17. Ramachandhiran, D.; Sankaranarayanan, C.; Murali, R.; Babukumar, S.; Vinothkumar, V. $\beta$-Caryophyllene promotes oxidative stress and apoptosis in KB cells through activation of mitochondrial-mediated pathway-An in-vitro and in-silico study. Arch. Physiol. Biochem. 2019, 4, 1-15. [CrossRef] 
18. Irrera, N.; D'Ascola, A.; Pallio, G.; Bitto, A.; Mazzon, E.; Mannino, F.; Squadrito, V.; Arcoraci, V.; Minutoli, L.; Campo, G.M.; et al. $\beta$-Caryophyllene Mitigates Collagen Antibody Induced Arthritis (CAIA) in Mice Through a Cross-Talk between CB2 and PPAR- $\gamma$ Receptors. Biomolecules 2019, 9, 326. [CrossRef]

19. Hashiesh, H.M.; Meeran, M.F.N.; Sharma, C.; Sadek, B.; Kaabi, J.A.; Ojha, S.K. Therapeutic Potential of $\beta$-Caryophyllene: A Dietary Cannabinoid in Diabetes and Associated Complications. Nutrients 2020, 12, 2963. [CrossRef]

20. Sköld, M.; Karlberg, A.T.; Matura, M.; Börje, A. The fragrance chemical beta-caryophyllene-air oxidation and skin sensitization. Food Chem. Toxicol. 2006, 44, 538-545. [CrossRef]

21. Lou, J.; Teng, Z.; Zhang, L.; Yang, J.; Ma, L.; Wang, F.; Tian, X.; An, R.; Yang, M.; Zhang, Q.; et al. $\beta$-Caryophyllene/Hydroxypropyl$\beta$-Cyclodextrin Inclusion Complex Improves Cognitive Deficits in Rats with Vascular Dementia through the Cannabinoid Receptor Type 2 Mediated Pathway. Front. Pharmacol. 2017, 8, 2. [CrossRef] [PubMed]

22. Santos, P.S.; Souza, L.K.M.; Araújo, T.S.L.; Medeiros, J.V.R.; Nunes, S.C.C.; Carvalho, R.A.; Pais, A.C.C.; Veiga, F.J.B.; Nunes, L.C.C.; Figueiras, A. Methyl- $\beta$-cyclodextrin Inclusion Complex with $\beta$-Caryophyllene: Preparation, Characterization, and Improvement of Pharmacological Activities. ACS Omega 2017, 2, 9080-9094. [CrossRef]

23. Santos, P.S.; Oliveira, T.C.; Júnior, L.M.R.; Figueiras, A.; Nunes, L.C.C. $\beta$-caryophyllene Delivery Systems: Enhancing the Oral Pharmacokinetic and Stability. Curr. Pharm. Des. 2018, 24, 3440-3453. [CrossRef] [PubMed]

24. Gertsch, J.; Leonti, M.; Raduner, S.; Racz, I.; Chen, J.Z.; Xie, X.Q.; Altmann, K.H.; Karsak, M.; Zimmer, A. Beta-caryophyllene is a dietary cannabinoid. Proc. Natl. Acad. Sci. USA 2008, 105, 9099-9104. [CrossRef]

25. Picciolo, G.; Pallio, G.; Altavilla, D.; Vaccaro, M.; Oteri, G.; Irrera, N.; Squadrito, F. $\beta$-Caryophyllene Reduces the Inflammatory Phenotype of Periodontal Cells by Targeting CB2 Receptors. Biomedicines 2020, 8, 164. [CrossRef]

26. Ceravolo, I.; Mannino, F.; Irrera, N.; Squadrito, F.; Altavilla, D.; Ceravolo, G.; Pallio, G.; Minutoli, L. Health Potential of Aloe vera against Oxidative Stress Induced Corneal Damage: An "In Vitro" Study. Antioxidants 2021, 10, 318. [CrossRef] [PubMed]

27. Pizzino, G.; Irrera, N.; Galfo, F.; Pallio, G.; Mannino, F.; D’amore, A.; Pellegrino, E.; Ieni, A.; Russo, G.T.; Calapai, M.; et al. Effects of the antagomiRs $15 \mathrm{~b}$ and $200 \mathrm{~b}$ on the altered healing pattern of diabetic mice. Br. J. Pharmacol. 2018, 175, 644-655. [CrossRef] [PubMed]

28. Pallio, G.; Micali, A.; Benvenga, S.; Antonelli, A.; Marini, H.R.; Puzzolo, D.; Macaione, V.; Trichilo, V.; Santoro, G.; Irrera, N.; et al. Myo-inositol in the protection from cadmium-induced toxicity in mice kidney: An emerging nutraceutical challenge. Food Chem. Toxicol. 2019, 132, 110675. [CrossRef] [PubMed]

29. Irrera, N.; Arcoraci, V.; Mannino, F.; Vermiglio, G.; Pallio, G.; Minutoli, L.; Bagnato, G.; Anastasi, G.P.; Mazzon, E.; Bramanti, P.; et al. Activation of A2A Receptor by PDRN Reduces Neuronal Damage and Stimulates WNT/ $\beta$-CATENIN Driven Neurogenesis in Spinal Cord Injury. Front. Pharmacol. 2018, 9, 506. [CrossRef]

30. Warr, D.; Hesketh, P. Cannabinoids as antiemetics: Everything that's old is new again. Ann. Oncol. 2020, 31, 1425-1426. [CrossRef] [PubMed]

31. McAllister, S.D.; Soroceanu, L.; Desprez, P.Y. The Antitumor Activity of Plant-Derived Non-Psychoactive Cannabinoids. J. Neuroimmune Pharmacol. 2015, 10, 255-267. [CrossRef]

32. Hinz, B.; Ramer, R. Anti-tumour actions of cannabinoids. Br. J. Pharmacol. 2019, 176, 1384-1394. [CrossRef]

33. Garofano, F.; Schmidt-Wolf, I.G.H. High Expression of Cannabinoid Receptor 2 on Cytokine-Induced Killer Cells and Multiple Myeloma Cells. Int. J. Mol. Sci. 2020, 21, 3800. [CrossRef] [PubMed]

34. Greenstein, S.; Krett, N.L.; Kurosawa, Y.; Ma, C.; Chauhan, D.; Hideshima, T.; Anderson, K.C.; Rosen, S.T. Characterization of the MM.1 human multiple myeloma (MM) cell lines: A model system to elucidate the characteristics, behavior, and signaling of steroid-sensitive and resistant MM cells. Exp. Hematol. 2003, 31, 271-282. [CrossRef]

35. Li, X.; Dou, J.; You, Q.; Jiang, Z. Inhibitors of BCL2A1/Bfl-1 protein: Potential stock in cancer therapy. Eur. J. Med. Chem. 2021, 220, 113539. [CrossRef]

36. Gugliandolo, A.; Pollastro, F.; Bramanti, P.; Mazzon, E. Cannabidiol exerts protective effects in an in vitro model of Parkinson's disease activating AKT/mTOR pathway. Fitoterapia 2020, 143, 104553. [CrossRef]

37. Ramakrishnan, V.; Kumar, S. PI3K/AKT/mTOR pathway in multiple myeloma: From basic biology to clinical promise. Leuk. Lymphoma 2018, 59, 2524-2534. [CrossRef]

38. Bongiovanni, D.; Saccomani, V.; Piovan, E. Aberrant Signaling Pathways in T-Cell Acute Lymphoblastic Leukemia. Int. J. Mol. Sci. 2017, 18, 1904. [CrossRef]

39. Gao, J.; Yu, S.R.; Yuan, Y.; Zhang, L.L.; Lu, J.W.; Feng, J.F.; Hu, S.N. MicroRNA-590-5p functions as a tumor suppressor in breast cancer conferring inhibitory effects on cell migration, invasion, and epithelial-mesenchymal transition by downregulating the Wnt- $\beta$-catenin signaling pathway. J. Cell. Physiol. 2019, 234, 1827-1841. [CrossRef]

40. He, L.; Zhou, H.; Zeng, Z.; Yao, H.; Jiang, W.; Qu, H. Wnt/ $\beta$-catenin signaling cascade: A promising target for glioma therapy. J. Cell. Physiol. 2019, 234, 2217-2228. [CrossRef] [PubMed]

41. Montalto, F.I.; De Amicis, F. Cyclin D1 in Cancer: A Molecular Connection for Cell Cycle Control, Adhesion and Invasion in Tumor and Stroma. Cells 2020, 9, 2648. [CrossRef]

42. Van Andel, H.; Kocemba, K.A.; Spaargaren, M.; Pals, S.T. Aberrant Wnt signaling in multiple myeloma: Molecular mechanisms and targeting options. Leukemia 2019, 33, 1063-1075. [CrossRef] [PubMed] 
43. Ding, L.; Cao, J.; Lin, W.; Chen, H.; Xiong, X.; Ao, H.; Yu, M.; Lin, J.; Cui, Q. The Roles of Cyclin-Dependent Kinases in Cell-Cycle Progression and Therapeutic Strategies in Human Breast Cancer. Int. J. Mol. Sci. 2020, 21, 1960. [CrossRef]

44. Gao, X.; Leone, G.W.; Wang, H. Cyclin D-CDK4/6 functions in cancer. Adv. Cancer Res. 2020, 148, 147-169. [CrossRef] [PubMed]

45. Misiewicz-Krzeminska, I.; Sarasquete, M.E.; Vicente-Dueñas, C.; Krzeminski, P.; Wiktorska, K.; Corchete, L.A.; Quwaider, D.; Rojas, E.A.; Corral, R.; Martín, A.A.; et al. Post-transcriptional Modifications Contribute to the Upregulation of Cyclin D2 in Multiple Myeloma. Clin. Cancer Res. 2016, 22, 207-217. [CrossRef] [PubMed] 